\title{
Investigação de temas CTS no contexto do pensamento latino-americano
}

\author{
Décio Auler \\ Demétrio Delizoicov \\ Universidade Federal de Santa Catarina
}

\section{Resumo}

Duas práxis, genuínas no contexto latino-americano, surgiram a partir dos anos 1960. 0 pensamento educacional de Paulo Freire e o denominado Pensamento Latino Americano em CTS (PLACTS). Com a articulação destas, no âmbito de uma compreensão ampliada sobre a não neutralidade da ciência-tecnologia, buscou-se responder à questão: como inserir demandas sociais, historicamente ignoradas, na produção do conhecimento científico-tecnológico? Numa síntese, destaca-se o potencial da investigação temática freireana reinventada no sentido de dar voz a novos atores sociais, num desafio de se detectarem manifestações locais de contradições e se identificarem novas demandas para agenda de pesquisa em CT.

Palavras-chave: Freire. Investigação temática. Inédito viável. PLACTS. Agenda de pesquisa. 


\section{Latin-American thinking on science and policy (PLACTS) and its proposals for scientific education}

Two genuine praxes arose in the Latin American context in the 1960s: the educational thinking of Paulo Freire and that known as Latin American Thinking in Science, Technology and Society (PLACTS). Through their correlation, in the realm of an expanded understanding of the non-neutrality of science and technology, an attempt was made to respond to the question: how can historically ignored social demands be included in the production of scientific and technological knowledge? This synthesis highlights the potential of the Freirian thematic investigation that was reinvented to give voice to new social actors, facing the challenge of detecting local manifestations of contradictions and identifying new demands for the research agenda in science and technology.

Keywords: Freire. Thematic investigation. Viable unprecedented. PLACTS. Research Agenda.

\section{Temas de investigación CTS en el contexto del pensamiento latinoamericano}

Dos praxis, genuinas en el contexto latinoamericano, surgieron a partir de los años 1960. El pensamiento educacional de Paulo Freire y el denominado Pensamiento Latinoamericano en CTS (PLACTS). Con la articulación de estas, en el ámbito de una comprensión ampliada sobre la no neutralidad de la Ciencia-Tecnológica, se buscó contestar la cuestión: ¿cómo incluir demandas sociales, históricamente ignoradas, en la producción del conocimiento científico-tecnológico? En una síntesis, se destaca el potencial de la investigación temática freiriana reinventada en el sentido de dar voz a los nuevos actores sociales, en un desafío de detectar manifestaciones locales de contradicciones e identificar nuevas demandas para la agenda de investigación en $C T$.

Palabras-clave: Freire. Investigación Temática. Inédito viable. PLACTS. Agenda de investigación. 


\section{Introdução}

Em alguns países da América Latina, em meados do século passado, surgem duas práxis, originais, enraizadas em elementos locais, compartilhando convicções muito próximas. Estamos nos referindo à práxis freireana e ao Pensamento Latino Americano em Ciência-Tecnologia-Sociedade (PLACTS)'1. Contudo, parece que, até o momento, elas não se realimentaram mutuamente de modo sistemático e frequente.

A práxis educacional do educador brasileiro Paulo Freire tem entre suas categorias centrais o diálogo e a problematização; pratica algo bastante inédito, no campo educacional, sobretudo ao se considerar que ela surge nos anos 1960. Contudo, currículos escolares, concebidos com a participação da comunidade escolar, são implementados, em algumas redes públicas de ensino, no Brasil, a partir do final dos anos 1980. 0 eixo estruturante desses currículos é o que se denomina de temas geradores, obtidos mediante um processo dialógico e problematizador sobre a realidade vivida pela comunidade escolar mais ampla, mediante uma investigação temática (Freire, 1987). Outra categoria, de sua práxis, é a curiosidade epistemológica, presente no processo de conceber e executar currículos, vinculada ao querer conhecer, a uma predisposição engajada diante do objeto de estudo. Essa é materializada no tema gerador, o qual representa manifestações locais de contradições presentes na sociedade mais ampla.

0 denominado PLACTS surge num momento histórico em que está em pauta a denominada transferência tecnológica. Esse pensamento empreende uma práxis que questiona este modelo de industrialização. Seus representantes, Varsavsky (1969, 1976), Herrera (1971, 1973) e Sábato (1982), dentre outros, na sua maioria, eram pesquisadores no campo das chamadas ciências naturais, vinculados a universidades argentinas. Eles, já nas décadas de 60 e 70, do século passado, destacavam que, no processo de transferência tecnológica, não estavam sendo transferidas ferramentas neutras, mas modelos de sociedade. Também afirmavam que a dinâmica do desenvolvimento científico-tecnológico era alheia, isto é, ignorava as demandas do conjunto da sociedade latino-americana. Propõem a concepção de uma política científico-tecnológica (PCT), de agendas de pesquisa a partir de demandas da maioria da sociedade, historicamente relegadas.

Trata-se de duas práxis assentadas em pressupostos comuns e complementares, conforme iremos argumentar ao longo deste texto. Complementares porque, se, de um lado, Freire trabalha dimensões bastante inéditas, no campo educacional, não se dedica a aprofundar o campo da ciência-

1. Segundo Dagnino (2008b), essa expressão foi sugerida por Dagnino, Thomas e Davyt para designar o conjunto das contribuições de cientistas latino-americanos, em especial dos argentinos Herrera, Sábato e Varsavsky. 
tecnologia - campo que constitui o foco do PLACTS que, por outro lado, está um tanto afastado do campo educacional. Constituem pressupostos comuns, visto que em ambos postula-se a superação da separação entre concepção e execução. Na concepção educacional bancária, foco principal da crítica de Freire, alguns concebem o currículo, outros o executam. No campo da ciência-tecnologia (CT), executa-se, no contexto latino-americano, segundo os representantes do PLACTS, uma agenda de pesquisa concebida no Hemisfério Norte.

Em ambos os referenciais, o ponto de partida, sinalizando novos horizontes, está em romper com esta separação entre conceber e executar, subvertendo a essência da lógica capitalista, conforme caracterizada, dentre outros, por Braverman (1987). O horizonte que vislumbramos é: conceber currículos, conceber agendas de pesquisa alimentadas por demandas de segmentos sociais historicamente relegadas. O encontro, a articulação destas duas caminhadas resulta em nova práxis, foco das considerações no presente artigo. A teorização resultante dessa caminhada sinaliza processos educacionais ampliados: processos ainda pontuais, incipientes, tênues, experienciados em contextos muito adversos.

Nesse processo, a investigação temática freireana constitui dimensão central. As demandas, os temas, os problemas nela identificados alimentam tanto a concepção de currículos escolares, quanto pesquisas, ainda pontuais, por exemplo, na universidade. Esse encaminhamento aproxima postulação de Dagnino (2010), contemporâneo do PLACTS, com práxis analisada por Freire na obra Extensão ou Comunicação (Freire, 2006). Dagnino propõe, considerando o tripé ensino-pesquisa-extensão, dinamizador do funcionamento da universidade, começar pela extensão, no sentido de internalizar demandas sociais. Como horizonte, propõe a transformação de demandas em problemas de pesquisa constituintes de uma agenda de pesquisa, de uma PCT.

No nosso entender, a teorização resultante da aproximação Freire-PLACTS permite a superação de um reducionismo, presente em encaminhamentos educacionais do campo CTS, identificado, por exemplo, em pesquisa de Rosa (2014). Ou seja, trata-se da postulação de uma participação da sociedade, em processos decisórios, sobre temas sociocientíficos, que vem se limitando a uma avaliação dos impactos da CT na sociedade, a uma avaliação no pós-concepção, no pós-produção de CT, na perspectiva de potencializar aspectos considerados positivos e mitigar os avaliados como negativos. Nessa participação, que pode ser considerada limitada, o papel da participação social está em tirar o melhor proveito desse desenvolvimento científico-tecnológico, considerado o único possível. 
A referida aproximação sinaliza a constituição de um processo educacional ampliado, contra-hegemônico, constituído a partir da articulação das duas referidas práxis. A caminhada empreendida, que culmina com teorização resultante dessa aproximação, inicia quando, no final dos anos 1970, na Guiné-Bissau, particularmente no campo das denominadas ciências naturais, realiza-se a transposição da concepção educacional freireana, inicialmente uma práxis relativa à educação não formal, para o âmbito da educação formal em escolas públicas (Muenchen, 2012; Delizoicov, 2008, 1983, 1980; Menezes, 1996; Pernambuco et al., 1988). Posteriormente, essa transposição, para o espaço da educação formal, ocorre também em algumas redes de ensino público no Brasil. (Delizoicov, N. et al. 2013; Saul e Silva, 2012; Delizoicov, 2008; Torres et al. 2002; Freire, 1995; Pontuschka, 1993)

Numa etapa seguinte, Auler (2002) e Auler e Delizoicov (2006a e 2006b), ocorre uma aproximação crítica entre Freire e repercussões educacionais do denominado movimento CTS, este com gênese no Hemisfério Norte. $\mathrm{Na}$ continuidade, a aproximação Freire-PLACTS passa por uma compreensão ampliada sobre a não neutralidade da CT (Delizoicov e Auler, 2011), aspecto que sinaliza para a necessidade de reinvenção de dimensão central em Freire, ou seja, a redução temática (Freire, 1987), etapa integrante da investigação temática.

A análise sobre essa caminhada constitui o escopo do presente artigo. A pergunta que guiou a reflexão, na aproximação Freire-PLACTS, foi: como inserir demandas locais, historicamente ignoradas, na produção do conhecimento científico-tecnológico? Quais procedimentos teóricometodológicos balizariam (ou parametrizariam) a busca e inserção dessas demandas de modo que se tornem problemas formulados na agenda de pesquisa?

\section{Aproximação Freire - movimento CTS}

Como síntese da teorização resultante da aproximação Freire-movimento CTS, balizada por investigações de caráter empírico, já publicadas, apresentamos os esquemas I e II. O esquema I representa uma compreensão pouco crítica sobre as interações entre CTS. Neste, as construções históricas superioridade/neutralidade do modelo de decisões tecnocráticas, a perspectiva salvacionista/redentora atribuída à CT e o determinismo 
tecnológico realimentam o modelo tradicional/linear de progresso². Essas construções estão apoiadas na suposta neutralidade da ciência-tecnologia (CT). No esquema II, está sintetizada a aproximação Freire-CTS.

\section{Esquema 1: Consciência ingênua}

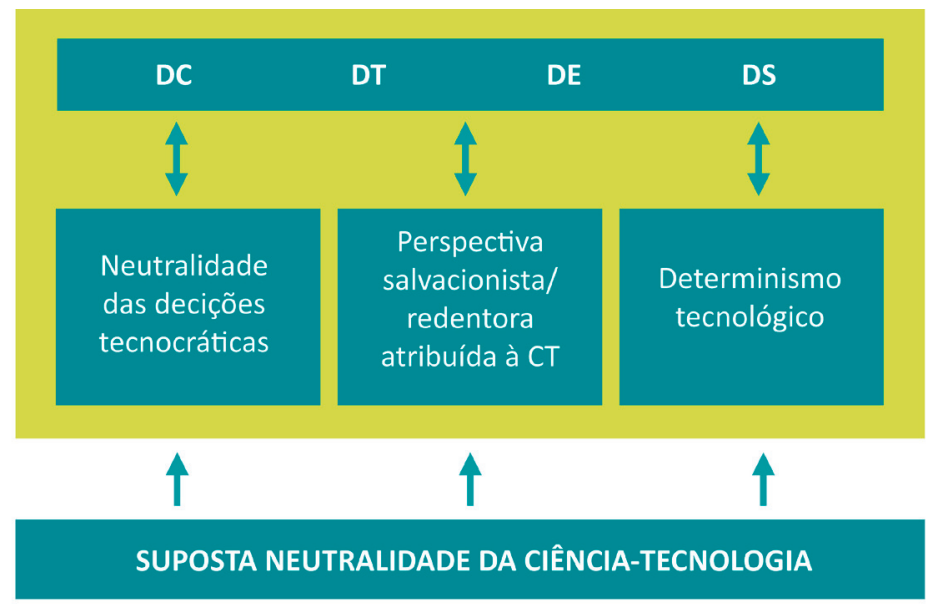

Fonte: Auler e Delizoicov, 2006a, p. 342

Esquema 2: Aproximação freire-cts

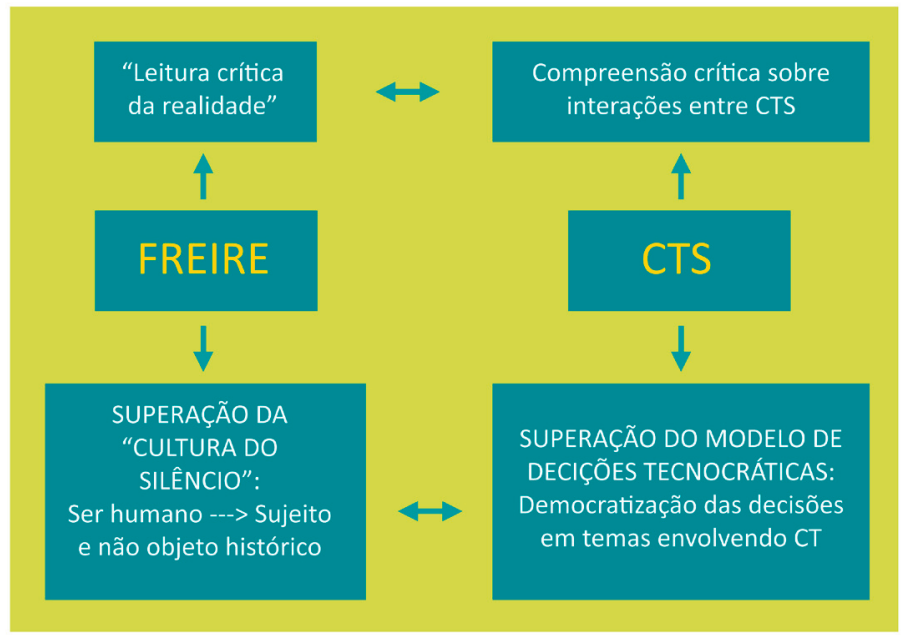

Fonte: Auler e Delizoicov, 2006b, p. 04

2. $\mathrm{DC}>\mathrm{DT}>\mathrm{DE}>\mathrm{DS}$ (modelo tradicional/linear de progresso). Nele, o desenvolvimento científico (DC) gera desenvolvimento tecnológico (DT); este gera o desenvolvimento econômico (DE) que determina, por sua vez, o desenvolvimento social (DS - bem-estar social). 
Para Freire (1987), educação relaciona-se com "conhecimento crítico da realidade", com "uma leitura crítica do mundo". Este se constitui no ponto central da referida aproximação: Para "uma leitura crítica do mundo", para o "desvelamento da realidade", uma compreensão crítica sobre as interações entre ciência-tecnologia-sociedade foi considerada como fundamental. Nesse sentido, a problematização, a busca de superação das referidas construções históricas sobre ciência-tecnologia-sociedade, consideradas pouco consistentes, foi incorporada em práxis executadas, por exemplo, Auler et. al (2005). Passouse a compreender melhor que uma postura fatalista, uma percepção ingênua da realidade poderia estar sendo realimentada por estas construções históricas denominadas de mitos, considerando que, dentre outras características, podem exercer efeito paralisante.

Ainda, em Auler e Delizoicov (2006a e 2006b) entende-se que os fatalismos, aos quais Freire constantemente faz referência, manifestavam-se, no campo científico-tecnológico, por exemplo, sob a forma de determinismos tecnológicos, em expressões do tipo "não podemos deter o avanço tecnológico"; "o desemprego no mundo é uma fatalidade do fim do século". Ou, então, o salvacionismo ${ }^{3}$ expresso em slogans como "os transgênicos acabarão com a fome no mundo" ou "fome zero com 100\% transgênico". Com essas compreensões, iniciávamos uma construção que utilizava categorias freireanas para trabalhar algo não aprofundado nas obras de Freire, ou seja, o campo científico-tecnológico. Entendíamos que a superação de uma percepção ingênua e mágica da realidade exigia, cada vez mais, uma compreensão dos sutis e delicados processos de interação entre CTS. Problematizávamos o superdimensionamento dado à tecnocracia em detrimento da democracia. Democracia pressupõe a possibilidade de escolha, de eleição entre várias possibilidades, entre vários caminhos. A racionalidade tecnocrática sustenta e legitima o pensamento do caminho único. Segundo essa lógica, para cada problema existe uma solução que seria a mais tecnicamente otimizadora. Essa racionalidade supostamente exclui opções políticas.

0 principal foco das críticas de Freire ao processo educacional hegemônico foi direcionado ao que denominou de educação bancária, postulando e praticando, em substituição a ela, a educação problematizadora. A bancária constitui-se num ato de depositar e consumir ideias - concepção materializada, nas ciências naturais, conforme nossa análise, em depositar, em reforçar construções históricas sobre CT, contribuindo para o que Freire denominou de "cultura do silêncio". No nosso entender, tal problematização precisava chegar ao campo

3. Exemplifica-se essa concepção analisando soluções adotadas, de forma generalizada, no contexto brasileiro, no que concerne à insegurança. Supostamente a solução contra a violência é técnica: muros cada vez mais altos, cercas eletrificadas, circuitos internos de TV. 
das ciências naturais, problematizando as referidas construções históricas. Em outros termos, uma reinvenção da concepção freireana deveria incluir uma compreensão crítica sobre as interações entre ciência-tecnologia-sociedade (CTS).

Mesmo com os avanços alcançados, até essa etapa, havia um sentimento de insatisfação, de incompletude. 0 caminho que seguimos consistiu em aprofundar, ampliar a compreensão sobre a não neutralidade da CT.

\section{Ampliação sobre a compreensão da não neutralidade da CT e o Pensamento Latino Americano em CTS}

Desde pesquisa realizada por Auler (2002), fortalecemos a convicção da pertinência de aprofundar a compreensão sobre a não neutralidade da CT. Convicção potencializada por um dos resultados dessa pesquisa, qual seja, uma compreensão confusa, ambígua sobre a não neutralidade apresentada em entrevista realizada com professores atuantes no campo das ciências da natureza. Também nela identificamos dimensão já discutida no item anterior. Ou seja, professores manifestaram passividade diante do desenvolvimento científico-tecnológico.

0 aprofundamento na compreensão sobre a não neutralidade, cujos resultados foram sintetizados em Delizoicov e Auler (2011), sinalizou para a pertinência do PLACTS no que tange a essa compreensão ampliada. Nesse artigo, "Ciência, Tecnologia e Formação social do espaço: questões sobre a não neutralidade" (Delizoicov; Auler, 2011), analisamos a temporalidade das teorias científicas e - lugar (espacialidade) em que conhecimentos científicos se originam, tendo por base a proposição de Milton Santos (1977) a respeito da formação social do espaço, com a finalidade de examinar a relação entre a dimensão espaçotemporal da ciência-tecnologia (CT) e a sua não neutralidade. Argumentamos que essa não neutralidade tem dois aspectos indissociáveis: um relativo à seleção da demanda e o outro relacionado à formulação científica de problemas originários da demanda e à correspondente busca de soluções.

Destacamos que a localização e seleção de problemas a serem investigados atende a distintos e conflitivos interesses que são priorizados num determinado tempo e num determinado espaço, uma vez que "o espaço não é uma simples tela de fundo inerte e neutro”, segundo Santos (1977, p. 89). Os critérios implicam, também, valores que direcionam a seleção de problemas a serem enfrentados.

Discutimos que há uma concepção hegemônica que faz crer que demandas relativas a especificidades históricas locais interessariam igualmente a qualquer 
espaço (geográfico) e em qualquer tempo (período histórico), uma vez que não explicita algo fundamental: há valores presentes na seleção e enfrentamento científico de demandas. É o campo axiológico que, também, tem seu papel na produção de CT. Ainda, segundo argumentação presente nesse artigo (Delizoicov; Auler, 2011), a não explicitação e compreensão da relação entre a seleção de demandas espaço-temporais e a formulação de problemas científicos tem levado a uma interpretação segundo a qual problemas particulares, originários de determinado espaço-tempo e com importância fundamental para ele, sejam transformados em universais, implicando que a demanda particular seja, também, transformada em universal. Sinalizamos que, possivelmente, pressupostos indutivistas estejam associados a essa concepção, ou seja, algo particular (demandas particulares) transformado em universal.

Consideramos, assim, que a não neutralidade da CT possui duas dimensões que se articulam de maneira indissociável: uma delas relacionada com a gênese das demandas e a outra com a gênese de respostas aos problemas científicos formulados a partir dessas demandas. Tal compreensão foi sinteticamente representada como

Esquema 3: Não neutralidade da ciência-tecnologia

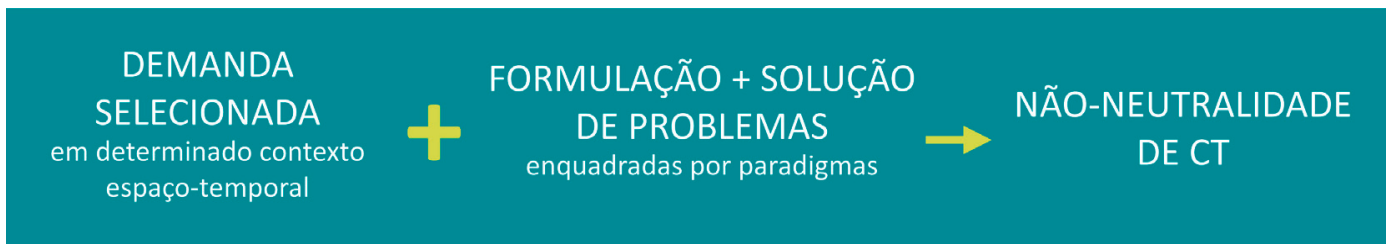

Fonte: Auler e Delizoicov, 2011, p. 267

No referido artigo, concluímos que, historicamente, demandas igualmente importantes, originárias de determinado espaço-tempo, podem não ter sido selecionadas para a formulação de problemas de pesquisa que contribuiriam para atendê-las, uma vez que, valorativamente, podem não ter sido consideradas como pertinentes para a agenda de pesquisa que se estabelece, no mesmo, ou em outros contextos espaço-temporais. Situações como essas, ainda não assumidas como problemas científicos a serem enfrentados, têm uma importância fundamental para o próprio processo de produção da CT, conforme podemos inferir: problemas, cuja origem teria esta característica, qual seja, de uma demanda não considerada, permanecem sem solução. Também, o enfrentamento desse tipo de demanda pode vir a conscientizar que os paradigmas existentes não seriam suficientes para a solução do problema que a partir dela se formula. Uma crise paradigmática 
poderia ser instalada, conforme diria Kuhn (1995).

A pertinência em aprofundar a compreensão sobre a não neutralidade da CT, assim como articulando, de forma ainda incipiente, Freire-PLACTS, pode ser identificada em pesquisas recentes (Monteiro, 2011; Strieder, 2012; Santos, 2012; Roso, Dalmolin e Auler, 2011; Rosa, 2014) realizadas no contexto brasileiro.

Já nas décadas de 60 e 70, do século passado, portanto, em outro tempo histórico, mas referindo-se ao espaço social da América Latina, Varsavsky, físico-matemático, pesquisador argentino, pioneiro do já citado PLACTS, havia compreendido que valores, presentes no espaço social mais amplo, eram definidores de problemas a serem investigados.

Em resumo, o que se investiga numa sociedade é o que essa sociedade considera suficientemente importante. Aimportância de um problema nada tem a ver com a verdade de suas possíveis respostas; depende dos valores (grifo do autor) predominantes sendo, portanto, uma característica ideológica. Diferentes estilos sociais fixarão diferentes prioridades - isto é, recursos - e farão a ciência progredir em direções diferentes. (Varsavsky, 1976, p.44)

\section{Continua Varsavsky,}

Se não estivermos dispostos a uma grande façanha de integração multinacional, com transformação simultânea de nossa estrutura social, segundo o modelo norteamericano, teremos que desenvolver em grande escala uma tecnologia própria e sua ciência de sustentação, que só existe em parte (grifo nosso). (Varsavsky, 1976, p.16)

E Varsavsky estava disposto a buscar um modelo social alternativo ao American way of life. Na obra "Por uma Política Científica Nacional", Varsavsky (1976) defende a tese central de que nem todo estilo científico é compatível com determinado estilo de sociedade. Ao analisar criticamente o estilo científico hegemônico, orientado a partir do Hemisfério Norte, particularmente dos EUA, sustenta que não é a quantidade de ciência produzida o indicador mais fiel de seu valor social. Mas seu conteúdo qualitativo. 0 investimento financeiro está voltado para o complexo industrial-militar ou para a satisfação de necessidades básicas de toda a população? Ou seja, o autor entende como fundamental uma análise do conteúdo qualitativo da ciência, dos diversos caminhos de desenvolvimento possíveis para esse conteúdo.

Varsavsky (1976, p. 14) destaca que "nossa ciência”, referindo-se ao contexto da América Latina, é certamente subdesenvolvida, "mas não porque não haja alcançado o nível norte-americano e, sim, porque é insuficiente para ajudar-nos 
a construir a sociedade que desejamos". Segundo ele, se quisermos que nossa sociedade seja parecida com a norte-americana, se desejamos viver como eles vivem, com modificações menores, "precisaremos da mesma ciência que eles" (Varsavsky, 1976p. 14). Mas, se quisermos outro tipo de sociedade, "Não fará falta uma ciência diferente? Diferente em que?". (Varsavsky, 1976, p. 14)

0 autor busca responder com o argumento,

Espero que isto não seja confundido com uma posição contra a ciência. 0 que se rejeita aqui é o conceito continuísta de a (grifo do próprio autor) ciência (...). Propõe-se, em compensação, algo muito mais difícil, como é o pensamento científico independente, capaz de criar uma (grifo do autor) ciência que, com o tempo, possa chegar a diferenciarse da ciência ortodoxa dirigida do Hemisfério Norte. (Varsavsky, 1976, p. 7-8)

Ao postular a independência cultural, a superação de uma atividade científica, na América Latina, que seja uma mera estação retransmissora do que é definido no Hemisfério Norte, defende, na introdução da obra, anteriormente mencionada, por exemplo, a necessidade de que novos problemas sejam investigados, de superação da metodologia de investigação "única”. Um pluralismo metodológico também, contemporaneamente, é reivindicado por Lacey (2008 e 2010). Varsavsky, na continuidade de suas considerações sobre a relação problema e produção científica, informa:

Procurarei mostrar também que, em geral, cada tipo de sociedade exige um estilo de ciência próprio, diferente pelo seu conteúdo, seus problemas prioritários, seus métodos de pesquisa e seus critérios práticos de verdade, assim como pelas características sociológicas do grupo de pesquisadores. (Varsavsky, 1976, p. 8)

Amilcar Herrera (1971), geógrafo, que inicia sua atuação na Argentina, vindo a atuar posteriormente como professor e pesquisador na UNICAMP, também precursor do PLACTS, argumentava que o principal problema, em termos de pesquisa e desenvolvimento, na América Latina, não eram suas deficiências quantitativas, mas seu descolamento da realidade latino-americana, dos problemas da região. Essa argumentação de Herrera, que constitui o eixo central do PLACTS, corresponde ao que, nesse artigo, tem sido discutido como demandas espaços-temporais não enfrentadas historicamente, não transformadas em problemas de pesquisa, não traduzidas em soluções para os problemas da região.

As postulações de Varsavsky e Herrera, feitas há mais de 50 anos, não se efetivaram. Suas análises, infelizmente, parecem cada vez mais atuais. Um grupo, cada vez menor, concebe; outros, a maioria da comunidade científica, executa. 
Contemporaneamente, parece que, cada vez mais, o pensamento único reina absoluto. Conforme analisa Seiler, "[...] os protagonistas centrais das inovações biotecnológicas são as grandes transnacionais químicas, farmacêuticas e alimentícias. Elas já dominam a agenda da pesquisa internacional" [grifo nosso]. (1998, p. 53)

A compreensão de que a gênese da não neutralidade da CT está na seleção de demandas teve, no PLACTS, contribuição significativa. Contribuição que problematiza a separação entre concepção e execução. Compreendemos melhor que Freire e o PLACTS constituem campos teóricos complementares. O PLACTS defende a concepção de uma agenda de pesquisa, de uma PCT a partir de demandas latino-americanas. Freire sustenta a concepção de currículos a partir de elementos locais, também latino-americanos. Em ambos, novos atores sociais entram em cena, verbalizando, colocando suas demandas em pauta.

\section{Aproximação Freire - PLACTS}

Com variadas perspectivas de análise, muitas vezes complementares, os autores, discutidos em Delizoicov e Auler (2011), assim como os do item anterior, têm convergido num ponto: historicamente, determinas demandas têm sido traduzidas em problemas de pesquisa, com consequente produção de conhecimento, enquanto outras têm sido ignoradas, postulando que uma possível consideração destas últimas tem ressonância com modelos de organização da sociedade.

Nesse sentido, retomando compreensão de Santos (1977), seria a presença de elementos materiais e imateriais, no espaço social, um espaço não vazio, não neutro, no qual valores tornados hegemônicos pautam o direcionamento dado à agenda de pesquisa; portanto, à produção do conhecimento. Assim, explicitada essa característica, como inserir demandas locais, historicamente ignoradas, na produção do conhecimento científico-tecnológico? Quais procedimentos teóricometodológicos balizariam (ou parametrizariam) a busca e inserção dessas demandas de modo que se tornem problemas formulados na agenda de pesquisa?

Entendemos que, para tal inserção, há vários caminhos, caminhos difíceis, mas não impossíveis. Por exemplo, Dagnino (2008a, 2008b e 2010), contemporâneo do PLACTS, prioriza sua atuação junto à comunidade de pesquisa. Nesse artigo, defendemos que processos educacionais podem contribuir para a constituição de uma cultura de participação que potencialize a entrada em cena de demandas desconsideradas, que influam na formulação de políticas públicas para CT, sensíveis às demandas do espaço social latino-americano. 
Dagnino, por um lado, em análise sobre a América Latina, conclui que, nesta região, a comunidade de pesquisa constitui-se no ator hegemônico no processo decisório da política científico-tecnológica (PCT). Comunidade que, segundo ele, ainda, em grande parte, endossa uma concepção de ciência-tecnologia neutras. Segundo esse autor, (Dagnino, 2008b), nesta região, a PCT é disfuncional. Suas sociedades, com uma sociedade civil frágil, são relativamente incapazes de inserir suas demandas na agenda, na PCT. Assim, a pesquisa é de qualidade, mas de relevância social questionável para o enfrentamento de situações contraditórias presentes nessa sociedade. A inserção dessas demandas tem sido foco de atuação do autor. Defende a necessidade de transformar problemas sociais em problemas de pesquisa, em problemas de conhecimento. Nesse sentido, sua atuação, majoritária, tem sido junto à própria comunidade de pesquisa, na perspectiva de que, ao menos parte dela, redirecione suas atividades.

Nesse artigo, outro caminho postulado, complementar ao anterior, consiste na compreensão de que a educação escolar, em seus vários níveis de ensino e, sobretudo, a que forma pesquisadores em CT constituem um elemento do espaço social mais amplo que pode potencializar a inserção de atores, historicamente excluídos, no processo de conhecimento, tal como caracterizado anteriormente, de tal forma que demandas destes, democrática e processualmente definidas, a partir de critérios também democráticos, sejam assumidas como problemas de pesquisa, problemas de conhecimento. Ou seja, busca-se, mediante processos educativos, potencializar a atuação da sociedade civil, de atuação frágil segundo Dagnino. Para tal, defende-se a pertinência da denominada investigação temática, proposta e praticada, originalmente, por Freire (1987). Por meio dela, uma equipe de pesquisadores identifica, num processo dialógico e participativo, as temáticas significativas que são próprias de uma unidade epocal, com características historicamente situadas, e que são manifestações locais de contradições sociais mais amplas, conforme também argumenta Santos (1977).

0 fato de a dialogicidade e a participação constituírem elementos fundamentais no planejamento e execução da investigação temática, conforme a análise de Freire (1987), permite, potencialmente, uma inserção diversificada de atores na definição das demandas com as quais se localizarão e formularão problemas e a correspondente contribuição para uma agenda de pesquisa. A investigação temática, que é objeto do terceiro capítulo do livro "Pedagogia do Oprimido" (Freire, 1987), inclui procedimentos para a obtenção e análise de dados que oferecem possibilidades para a localização de demandas oriundas de especificidades espaços-temporais que contribuem para a identificação e formulação de problemas de investigação.

Uma síntese do processo de investigação temática, que é realizada em cinco 
etapas, pode ser assim caracterizada: $1^{\text {a) }}$ Levantamento preliminar: faz-se um levantamento das condições da localidade, onde, por meio de fontes secundárias e conversas informais com os indivíduos, realiza-se a "primeira aproximação" e uma recolha de dados; $2^{\text {al }}$ Análise das situações e escolha das codificações: faz-se a escolha de situações que encerram contradições vividas e a preparação de suas codificações que serão apresentadas na etapa seguinte; 3a) Diálogos descodificadores: os investigadores voltam ao local para, nos círculos de investigação temática, realizar os diálogos descodificadores. Essa etapa culmina com a obtenção dos temas geradores; $4^{\mathrm{a}}$ ) Redução temática: a partir do trabalho de uma equipe interdisciplinar, identificam-se e selecionam-se conhecimentos necessários à compreensão dos temas identificados na etapa anterior. Consiste na elaboração do programa a ser desenvolvido na quinta etapa e 5a) Trabalho em sala de aula: somente após as quatro etapas anteriores, com o programa estabelecido e o material didático preparado, ocorre o trabalho de sala de aula. Para uma compreensão mais ampla dessas etapas, implementadas em escolas pertencentes a redes públicas, pode-se consultar Delizoicov (1983,1991e 2008). Esse processo, originalmente concebido para a educação de jovens e adultos, no espaço de educação não formal (Freire, 1987 e 2006), foi posteriormente transposto para o espaço da educação formal, conforme historiado e referenciado anteriormente.

Coerente e passível de articulação com o exposto situa-se proposição de Dagnino (2010), considerada como um dos caminhos possíveis, a qual busca um redirecionamento das atividades de pesquisadores - redirecionamento que implica iniciar pela extensão ${ }^{4}$, considerando o tripé ensino-pesquisa-extensão que caracteriza as atividades desenvolvidas na Universidade. Ao termo extensão associa-se o conceito de intenção. "Intenção no sentido de internalizar a agenda de discussão social como diretriz" (Dagnino, 2010, p. 286). Em outros termos, internalizar, trazer para dentro da universidade, demandas sociais que alimentarão o ensino e a pesquisa.

Assim, atividades da universidade estão orientadas por uma prática que busca ajudar a resolver tais problemas "com um agregado de conhecimentos". Demandas, problemas sociais transformados em problemas de pesquisa, em problemas de conhecimento. Também, o enfrentamento, a resolução destes problemas, segundo o autor, não podem ficar restritos aos enfoques disciplinares hegemônicos neste âmbito. Entende que os problemas, particularmente os sociais, não podem ser “etiquetados" disciplinarmente. Para Dagnino (2010, p. 285), “nenhum problema

4. Este encaminhamento é próximo daquele defendido por Freire em "Extensão ou Comunicação?" (Freire, 2006), obra na qual há uma crítica à concepção de extensão que consiste em ofertar para a comunidade local/ regional, um conhecimento, muitas vezes, não demandado por problemas daquela comunidade". 
social vem com uma etiqueta que diga 'eu sou da sociologia', 'eu sou da economia', "eu sou da antropologia' [...] os problemas são multidisciplinares".

Sintetizando, o conjunto das reflexões, presentes nesse texto, permite sinalizar um possível encaminhamento para o questionamento explicitado, no início deste item, ou seja, como inserir demandas locais, historicamente ignoradas, na produção do conhecimento científico-tecnológico? Entendemos que, mediante o processo de investigação temática, dando voz a novos atores sociais - inclusive pesquisadores em CT formados contra-hegemonicamente numa perspectiva que tem sintonia com o PLACTS -, novos valores emergem e novas demandas são colocadas em pauta. Por intermédio de processos educativos - numa dinâmica que articula escolas de educação básica, comunidade e setores da academia -, colocam-se em pauta demandas negligenciadas historicamente, as quais desempenham um duplo papel. De um lado, a estruturação de currículos em torno dos temas, dos problemas demandados. De outro, a transformação desses em problemas de pesquisa - investigação efetivada por equipes de pesquisadores em CT que participam do processo de investigação temática na perspectiva freireana. Tal como postulado por Dagnino, essa dinâmica requer a constituição de coletivos multidisciplinares, incluindo leigos ainda que com formação não especializada em alguma área. Esses, como participantes da investigação temática, dão a sua contribuição para a agenda de pesquisa e parâmetros para o encaminhamento e enfrentamento de demandas.

Iniciamos o artigo destacando o potencial, resultante da aproximação FreirePLACTS, para a constituição de processos educativos crítico-transformadores, para a superação da lógica que separa concepção de execução. Uma lógica em que alguns, poucos, concebem e outros, a maioria, executam. Entendemos que o processo de investigação temática, conforme argumentamos anteriormente, fundamenta e instrumentaliza processos participativos que, colocando em cena novos atores, colocam em pauta novos valores, novas demandas que podem alimentar a concepção e a execução de novas agendas de pesquisa, de novas configurações curriculares.

Esse encaminhamento sinaliza novos horizontes para o movimento CTS. Dentre outros autores, Auler (2007, 2011) e Strieder (2012) vêm alertando para a necessidade de um olhar mais criterioso na transposição de objetivos, programas e conceitos, elaborados no Hemisfério Norte, os quais carregam as marcas dos valores predominantes naquele espaço-tempo. Nesse sentido, entendemos como necessário um olhar ampliado sobre o conceito de participação.

Muitas das repercussões de CTS, no campo educacional, no Hemisfério Norte, manifestando-se também no contexto brasileiro, conforme pesquisa realizada por Rosa (2014), estão marcadas por uma concepção hegemônica de participação 
que pode ser sintetizada por algumas ideias chaves: avaliar impactos do desenvolvimento científico-tecnológico na sociedade; avaliar aspectos positivos e negativos, na sociedade, de determinado desenvolvimento científico-tecnológico. Em outros termos, considera-se a CT como dada, e a participação é reduzida a mensurar efeitos desta CT na sociedade, cabendo a ela tirar o melhor proveito possível. Essa participação, em alguns âmbitos, é denominada de avaliação tardia da tecnologia. Assume-se, muitas vezes, uma postura fatalista diante dos rumos dados ao desenvolvimento científico-tecnológico.

Sem desconsiderar contribuições de CTS, do Hemisfério Norte, entendemos que as reflexões, presentes neste artigo, sinalizam encaminhamento teóricometodológico que potencializa uma maior participação do conjunto da sociedade em processos decisórios - participação naquilo que é essencial, não apenas quando as decisões centrais já foram tomadas; participação na concepção e não apenas na execução. Esta "pseudoparticipação”, ou a impressão de estar participando, ocorre sempre após a definição do essencial: após a definição do currículo nas escolas, após a definição da agenda de pesquisa (das políticas públicas, por exemplo, para a ciência-tecnologia), após o consumo/uso de produtos (cabe à sociedade reciclar), sem uma participação na discussão do que é produzido para consumir. Ocorre sem uma problematização da agenda de pesquisa capturada pela teoria da inovação, a serviço da lógica consumista, da obsolescência programada, geradora de insustentabilidade socioambiental.

\section{Reinvenção da investigação temática, sinalizadora de novos horizontes em processos formativos}

Conforme destacado anteriormente, Varsavsky, pioneiro do PLACTS, trouxe contribuições significativas para a reflexão sobre especificidades de espaços sociais distintos, problematizando a denominada transferência tecnológica, o endosso a uma agenda de pesquisa única. Em suas palavras,

Propõe-se, em compensação, algo muito mais difícil, como é o pensamento científico independente, capaz de criar uma (grifo do autor) ciência que, com o tempo, possa chegar a diferenciar-se da ciência ortodoxa dirigida do hemisfério norte. (Varsavsky, 1976, p, 8)

Ou, “hoje em dia, da totalidade do saber científico, que parte é útil à construção do estilo de desenvolvimento almejado?" (Varsavsky, 1976, p. 36)

Contemporaneamente, esta postura seletiva, em relação ao conhecimento 
científico-tecnológico disponível, é trabalhada por Dagnino (2008a) mediante o que denomina de adequação sociotécnica (AST). As sete modalidades da AST ${ }^{5}$ - descritas pelo autor, sintetizam encaminhamentos dados junto a Redes de Economia Solidária, Incubadoras Tecnológicas de Cooperativas Populares, Fábricas Recuperadas e Cooperativas Populares.

No início deste artigo, destacamos a incompletude, o não aprofundamento, na práxis freireana, do campo científico-tecnológico. Com a intenção de avançar neste âmbito, buscando uma articulação Freire-PLACTS, apoiamo-nos em categoria empregada por Freire (1987), o inédito viável. Para esse educador, temas/problemas identificados, na referida investigação temática, precisam ser problematizados de modo que se busquem soluções ainda não percebidas para os problemas que se formulam durante o processo de problematização. Essas soluções seriam o que Freire denomina de inédito viável. Podemos compreendêlo como novidades em CT originárias da solução de problemas formulados a partir de demandas historicamente excluídas da agenda de pesquisa. Demandas detectadas mediante o processo de investigação temática, orientado para a obtenção de manifestações espaço-temporais de contradições nas localidades onde se realiza essa investigação.

Em nossa análise, dar voz a atores sociais historicamente excluídos, silenciados, transformando demandas negligenciadas, presentes em espaços sócio-temporais pertencentes à América Latina, em problemas de pesquisa, mediante a investigação temática, constitui possibilidade em processo de desvelamento. Parece que a própria investigação temática seria, também, um inédito viável para práticas educativas e de pesquisa numa perspectiva CTS em sintonia com as concepções do PLACTS e de Freire. 0 que estamos buscando desvelar consiste no fato de que "soluções ainda não percebidas" talvez não sejam encontráveis buscandoas, unicamente, em conhecimentos já disponíveis, originários possivelmente de demandas distintas das que uma investigação temática poderia detectar e que ainda não se constituíram em problemas de investigação para CT. Assim, o inédito viável pode estar em duas dimensões: 1) na constatação de que a busca de soluções, para demandas latino-americanos, tenha como ponto de partida a transformação de problemas, negligenciados historicamente, em problemas que geram conhecimentos e práticas ainda não constituídas e 2) no processo pelo qual se realiza a busca e a formulação destes problemas. 0 que estamos propondo é que este se constitua numa investigação temática.

Essa análise remete à necessidade de problematizar, de reinventar etapa 
presente no processo da investigação temática freireana, com a finalidade de que se possa tê-la como orientação para a construção de políticas públicas para a CT em sintonia com o PLACTS. Haveria, nesse sentido, uma incompletude, possivelmente vinculada ao mencionado não aprofundamento do campo científico-tecnológico, a ser enfrentada para o desenvolvimento da etapa da redução temática, integrante da investigação temática. Freire assim a caracteriza:

Feita a delimitação temática, caberá a cada especialista, dentro de seu campo, apresentar à equipe interdisciplinar o projeto de "redução" de seu tema. No processo de "redução" deste, o especialista busca os seus núcleos fundamentais que, constituindose em unidades de aprendizagem e estabelecendo uma seqüência entre si, dão a visão geral do tema "reduzido". (Freire, 1987, p. 66)

Nessa compreensão, o que está implícito é que, para a redução do tema identificado, realizada por especialistas de várias áreas, o conhecimento acumulado historicamente é selecionado para parametrizar currículos e programas de ensino. Desse modo, o processo educativo contribui para problematizar os temas geradores no sentido da busca da sua superação por meio de conhecimentos, ainda, inéditos para os estudantes, mesmo que já constituídos historicamente.

Contudo, à luz das discussões realizadas, ao longo deste artigo, pode-se conceber um tema CTS como um tema gerador caracterizado como demanda ainda não assumida pela pesquisa em CT, não traduzida em problema de pesquisa não investigado. Nessa situação, haveria conhecimento disponível para o procedimento caracterizado por Freire, ou seja, a redução temática? Duas situações, pelo menos, precisam ser consideradas. No caso de haver conhecimentos e práticas já disponíveis, equipes multidisciplinares se dedicariam ao enfrentamento do problema de modo que a demanda pudesse ser atendida. Situação muito distinta ocorreria no caso de haver a consciência, das equipes multidisciplinares, de que, para o enfrentamento do problema, o conhecimento e as práticas historicamente constituídas ainda não são suficientes. Este parece ser o caso ao qual Varsavsky (1976) e Dagnino (2008a), dentre outros, engajados no PLACTS, estão se referindo.

Em outros termos, ainda que a investigação temática, na perspectiva freireana, possa ser orientadora de processos de produção em CT, a sua reinvenção, na etapa de redução temática, é um imperativo, de modo que possa subsidiar a proposição de projetos de pesquisa em CT, em sintonia com as concepções de Freire e do PLACTS.

Processos formativos, inspirados na investigação temática reinventada, orientados para a localização e enfrentamento de demandas historicamente negligenciadas, com produção de conhecimento novo, constituem o horizonte 
sinalizado neste artigo - processos viabilizados em coletivos multidisciplinares, envolvendo qualquer nível de ensino, comunidade e pesquisadores comprometidos politicamente com a busca de transformações sociais mais amplas. Entendemos que um processo formativo emancipador e crítico-transformador constitui uma exigência para a implementação dos pressupostos do PLACTS.

Defendemos uma complementariedade que articula um fazer educativo (Freire) e um fazer pesquisa (PLACTS), em que currículos e agenda de pesquisa são gerados num processo coletivo de aprendizagem. Como encaminhamento propomos que temas, que passamos a denominar temas CTS, os quais têm como característica constituírem demandas historicamente relegadas, assumam o papel de temas geradores, gerando currículos, nos vários níveis de ensino, e agendas de pesquisa.

\section{Bibliografia}

AULER, Décio. Interações entre ciência-tecnologia-sociedade no contexto da formação de professores de ciências. 2002. Tese (Doutorado em Educação), Centro de Educaçao, Universidade Federal de Santa Catarina, Florianópolis - SC, 2002.

AULER, Décio; et al. Transporte Particular X Coletivo: intervenção curricular pautada por interações entre ciência-tecnologia-sociedade. Enseñanza de las Ciencias. Barcelona - ESP, Número Extra, pp. 1-5. 2005.

AULER, Décio; DELIZOICOV, Demétrio. Ciência-Tecnologia-Sociedade: relações estabelecidas por professores de ciências. Revista Electrónica de Enseñanza de las Ciencias, Vigo, v. 5, n; 2, pp. 337-355, 2006a.

AULER, Décio; DELIZOICOV, Demétrio. Educação CTS: Articulação entre Pressupostos do Educador Paulo Freire e Referenciais Ligados ao Movimento CTS. In: Seminário Ibérico CTS em la Enseñanza de las Ciencias. Anais... Málaga: Universidad de Málaga, 2006b.

AULER, Décio. Enfoque Ciência-Tecnologia-Sociedade: pressupostos para 0 contexto brasileiro. Ciência \& Ensino, Campinas - SP, v. 1, n. Especial, p. 01-20, 2007.

AULER, Décio. Novos caminhos para a educação CTS: ampliando a participação. In: SANTOS, Wildson Luiz Pereira dos; AULER, Décio (Orgs.). CTS e Educação Científica: desafios, tendências e resultados de pesquisas. Brasília - DF: Universidade de Brasília, 2011, pp. 73-98.

BRAVERMAN, Harry. Trabalho e capital monopolista: a degradação do trabalho no século XX. Rio de Janeiro - RJ: LTC, 1987. 379p.

DAGNINO, Renato Peixoto. Neutralidade da ciência e determinismo tecnológico: um debate sobre a tecnociência. Campinas - SP: Unicamp, 2008a. 
DAGNINO, Renato Peixoto. As Trajetórias dos Estudos sobre Ciência, Tecnologia e Sociedade e da Política Científica e Tecnológica na Ibero-América. Alexandria, Florianópolis - SC, v. 1, n. 2, pp. 3-36, 2008b

DAGNINO, Renato. Uma estória sobre Ciência e Tecnologia, ou Começando pela extensão universitária... In: DAGNINO, Renato. (Org.). Estudos sociais da ciência e tecnologia e política de ciência e tecnologia: abordagens alternativas para uma nova América Latina. Campina Grande - PB: EDUEPB, pp. 281-311, 2010.

DELIZOICOV, Demétrio. Uma experiência em ensino de ciências na Guiné Bissau Depoimento. Revista de Ensino de Física, v. 2, n. 4, pp. 57-72, 1980.

DELIZOICOV, Demétrio. 0 ensino de física e a concepção freiriana da educação. Revista de Ensino de Física, v. 5, n. 2, pp. 85-98, dez. 1983.

DELIZOICOV, Demétrio. Conhecimento, tensões e transições. 1991. Tese (Doutorado em Educação), Faculdade de Educação, Universidade de São Paulo, São Paulo SP, 1991.

DELIZOICOV, Demétrio. La Educación en Ciencias y la Perspectiva de Paulo Freire. Alexandria, Revista de Educação em Ciência e Tecnologia, v.1, n.2, pp.37-62, 2008.

DELIZOICOV, Demétrio; AULER, Décio. Ciência, Tecnologia e Formação Social do Espaço: questões sobre a não-neutralidade. Alexandria, Revista de Educação em Ciência e Tecnologia, Florianópolis - SC, v. 4, n. 2, pp. 247-73, 2011.

DELIZOICOV, Nadir Castilho; STUANI, Geovana Mulinari; DELIZOICOV, Demétrio. Reorientação Curricular na Concepção Freireana de Educação: análises em dissertações. Revista e-Curriculum, São Paulo - SP, v. 03, n. 11, pp. 684-712, 2013. FREIRE, Paulo. Educação na cidade. São Paulo - SP: Cortez, 1995.

FREIRE, Paulo. Pedagogia do Oprimido. 17 Ed. Rio de Janeiro - RJ: Paz e Terra, 1987.

FREIRE, Paulo. Extensão ou comunicação? 13a ed. São Paulo - SP. Paz e Terra, 2006.

HERRERA, Amílcar Oscar. Ciencia y política en América Latina. 8 ed. México: siglo XXI editores, 1971.

HERRERA, Amílcar Oscar. Los determinantes sociales de la política científica en América latina. Política científica explícita y política científica implícita. Revista de Ciências Sociais, v. 13, n. 49, pp. 98-112, 1973.

KUHN, Thomas. A estrutura das revoluções científicas. $5^{a}$ ed. São Paulo: Perspectiva, 1995.

LACEY, Hugh. Valores e atividade científica 1. São Paulo: Editora 34, 2008.

LACEY, Hugh. Valores e atividade científica 2. São Paulo: Editora 34, 2010.

MENEZEZ, Luiz Carlos de. Paulo Freire e os físicos. In: GADOTTI, Moacir (Org.) Paulo Freire uma biobibliografia. São Paulo: Ed. Cortez: Instituto Paulo Freire; Brasília, DF: UNESCO. 1996. 
MONTEIRO, Renata da Silva. Entre monoculturas e ecologias: as percepções do público dos museus de ciência e técnica sobre as relações ciência, tecnologia, sociedade e ambiente (CTSA) 2011. Dissertação (Mestrado em Educação), Universidade Federal do Rio de Janeiro, Rio de Janeiro - RJ, 2011.

MUENCHEN, Cristiane, DELIZOICOV Delizoicov. A Construção de um Processo Didático-Pedagógico Dialógico: aspectos epistemológicos. Ensaio: Pesquisa em Educação em Ciências, Belo Horizonte - MG, v. 14, n. 3, pp. 1-20, 2012.

PERNAMBUCO, Marta Maria Castanho; DELIZOICOV, Demétrio; ANGOTTI, José André. Projeto ensino de ciências a partir de problemas da comunidade. In: Seminário Ciência Integrada e/ou Integração entre as Ciências: teoria e prática, Rio de Janeiro - RJ. Atas..., Rio de Janeiro - RJ, 1988.

PONTUSCHKA, Nídia (Org.) Ousadia no diálogo - Interdisciplinaridade na escola pública. São Paulo - SP: Edições Loyola, 1993.

ROSA Suiane Ewerling da. Não neutralidade da Ciência-Tecnologia: problematizando silenciamentos em práticas educativas relacionadas a CTS. 2014. Dissertação (Mestrado em Educação), Universidade Federal de Santa Maria, Santa Maria - RS, 2014.

ROSO, Caetano Castro; DALMOLIN, Antônio Marcos Teixeira; AULER, Décio. Extensão ofertista ou diálogo com a comunidade: o que tem pautado a extensão universitária?. In: XI Congreso IberoAmericano de Extensión Universitaria, 2011, Santa Fé. Anais..., Santa Fé, Argentina: Universidad Nacional del Litoral, 2011. pp. 01-12.

SÁBATO, Jorge A.; MACKENZIE, Michael. La producción de tecnología: autónoma o transnacional. Ciudad de México - MEX: Editorial Nueva Imagen, 1982.

SANTOS, Milton. Sociedade e espaço: a formação social como teoria e como método. Boletim Paulista de Geografia, São Paulo - SP: AGB, pp. 81-99, 1977.

SANTOS, Rosemar Ayres. Não neutralidade na perspectiva educacional ciênciatecnologia-sociedade. 2012. Dissertação (Mestrado em Educação), Universidade Federal de Santa Maria, Santa Maria - RS, 2012.

SAUL, Ana Maria; SILVA, Antônio Fernando Gouvêa da. 0 pensamento de Paulo Freire em sistemas públicos de ensino: pesquisando políticas de currículo em um mesmo território, sob diferentes olhares. Revista Teias, Rio de Janeiro - RJ, v. 13, n. 27, pp. 9-26, 2012.

SEILER, Achim. Biotecnologia e Terceiro Mundo: interesses econômicos, opções técnicas e impacto socioeconômico. In: ARAÚJO, Hermetes Reis de. Tecnociência e cultura: ensaios sobre o tempo presente. São Paulo: Estação Liberdade, 1998. STRIEDER, Roseline Beatriz. Abordagens CTS na educação científica no Brasil: sentidos e perspectivas. 2012. Tese (Doutorado em Ensino de Ciências), Instituto de Física, Instituto de Química, Instituto de Biociências e Faculdade de Educação, 
Universidade de São Paulo, São Paulo - SP, 2012.

TORRES, Carlos Alberto; O'CADIZ, Maria del Pilar; WONG, Pia Lindquist. Educação e democracia: a práxis de Paulo Freire em São Paulo. São Paulo - SP: Cortez, 2002. VARSAVSKY, Oscar. Ciencia, política y cientificismo. Buenos Aires: Centro Editor de América Latina, 1969.

VARSAVSKY, Oscar. Por uma política científica nacional. Rio de Janeiro - RJ: Paz e Terra, 1976.

Recebido em julho de 2014 Aprovado em dezembro de 2014

Décio Auler é doutor em educação - ensino de ciências naturais, pela Universidade Federal de Santa Catarina e professor associado II da Universidade Federal de Santa Maria. E-mail: auler.ufsmagmail.com

Demétrio Delizoicov é doutor em educação pela Universidade de São Paulo e professor associado IV da Universidade Federal de Santa Catarina. E-mail: demetrio.netodufsc.br 